\title{
Improved antimicrobial activity of silica-Cu using a heteropolyacid and different precursors by sol-gel: synthesis and characterization
}

\author{
Romina Arreche $^{1} \cdot$ Natalia Bellotti $^{2} \cdot$ Mirta Blanco $^{1} \cdot$ Patricia Vázquez $^{1}$ (D)
}

Received: 14 January 2015/Accepted: 10 April 2015/Published online: 24 April 2015

(C) Springer Science+Business Media New York 2015

\begin{abstract}
Antimicrobial coatings are used to avoid the proliferation of fungi and bacteria inside urban buildings by incorporating low concentrations of antimicrobial agents (biocides). This study is focused on evaluating the antifungal activity of copper (II) supported on a silica matrix, and as counter-cation of a heteropolyacid, obtained from the sol-gel method using various catalysts, against two fungal isolates. The fungi used in this evaluation were Alternaria alternata and Chaetomium globosum isolated by routine microbiological techniques from biodeteriorated paints films. In all cases, fungi were selected due to their ability to grow on the paint films and their negative impact on human health. First, silicas were prepared using tetraethylorthosilicate and methyl trimethoxysilane as precursors and acetic acid, hydrochloric acid as catalysts of the hydrolysis reaction of the alkoxide. The effect of addition of copper (II) in the form of copper nitrate was studied. With respect to the morphology of the silica, most of them are similar, between pure and modified silica, in all cases. Once the stage of the synthesis and characterization of the prepared materials was performed, six of them were selected to evaluate their antifungal activity by agar plate inhibition test against both fungi of interest (A. alternata and $C$. globosum), and the percent inhibition was
\end{abstract}

Patricia Vázquez

pgvazquez@hotmail.com

1 CINDECA-Centro de Investigación y Desarrollo en Ciencias Aplicadas, "Dr. Jorge J. Ronco," CCT La Plata, CONICET-Departamento de Química, Facultad de Ciencias Exactas, UNLP, 47 No. 257 (1900), La Plata, Buenos Aires, Argentina

2 CIDEPINT-Centro de Investigación y Desarrollo en Tecnología de Pinturas (CIC-CONICET), Calle 52 e/121 y 122, (1900), La Plata, Buenos Aires, Argentina determined in each case. Tested Cu-based solids were shown to have a higher antifungal activity because they completely inhibit the growth of both fungi with lower concentrations relative to its control. This work was performed as a preliminary study, in order to guide the selection of a suitable organic biocide from a list of possible antifungal agents.

Graphical Abstract

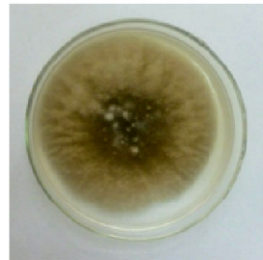

(a) Control

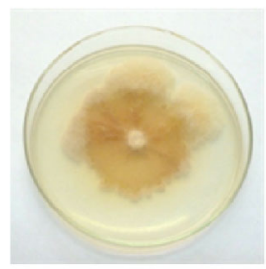

(d) Control

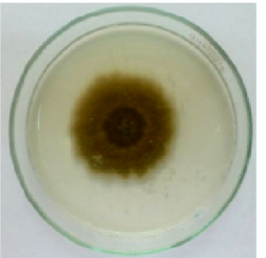

(b) SM-H

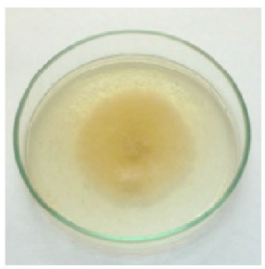

(e) SM-H

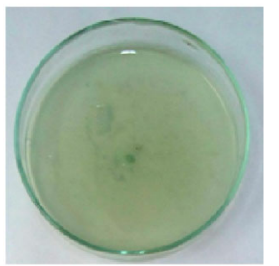

(c) $\mathrm{SM}-\mathrm{HCu}$

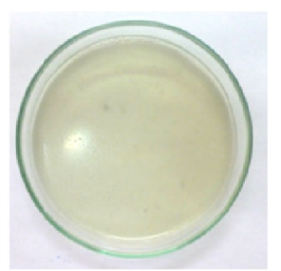

(f) $\mathrm{SM}-\mathrm{HCu}$
Keywords Antimicrobial coatings - Silica - Copper . Sol-gel method $\cdot$ Antifungal activity

\section{Introduction}

There is a global concern about microbial colonization, especially on clinical and food industrial surfaces $[1,2]$. It is well known that the microorganisms attach to diverse substrates, multiply and embed in the extracellular polymeric 
substance matrix they produce [3, 4]. This development, called biofilm, provides a higher resistance of the comprised microorganisms to hydrodynamic shear forces, biocides or antibiotics [4, 5]. Therefore, prevention of microorganisms colonization is clearly necessary, especially fungal proliferation which recently was strongly associated with infections, respiratory symptoms, allergies, asthma and immunological reactions [6, 7]. On the other hand, they are also involved in the deterioration and degradation of both synthetic and natural materials, secreting enzymes and organic acids during their metabolic process [8]. Among the microorganisms that colonize the indoor environment, fungi are considered the most damaging $[9,10]$.

The development of new materials or coatings might prevent microbial colonization, but to make this possible they must contain bioactive agents (called biocides) [5, 11], usually present in low concentrations as additives [11]. At the present time, the tendency in the antimicrobial formulation is to replace the traditional biocides with environmentally friendly ones [12].

These kinds of coatings are obtained by adding metals (e.g., silver or copper), germicides (e.g., triclosan), natural bioactive compounds (e.g., peptides) or by other methods (e.g., light-activated antimicrobials, bioactive polymers [1, 13]). Silica matrix has several advantages such as: highpurity precursors, homogeneity of the chemically inert, stable and homogeneously obtained material and can be designed to act as a reservoir for releasing antimicrobial agents over extended time periods $[14,15]$.

Recent works have focused on the antifungal efficiency of different particulate metals $[16,17]$. The antimicrobial properties of copper, silver, titanium and zinc are effective in the reduction in diverse microorganisms growth [18-21].

The Green chemistry main target is to make new chemical processes or change the existing ones so that they will be more benign for the environment. This is why the need to develop clean technologies rises. A sustainable development is obtained when new technologies are provided to society to cover their needs but with responsibility toward the environment $[22,23]$.

The main goal of this work is the synthesis and characterization of mixed materials based on silica prepared by the sol-gel method, using tetraethylorthosilicate (TEOS) and methyltrimethoxysilane (MTMS) as precursors; acetic acid, hydrochloric acid and a heteropolyacid (HPA) as hydrolysis catalysts. Also, this HPA was incorporated along with copper nitrate $\left(\left(\mathrm{NO}_{3}\right)_{2} \mathrm{Cu}\right)$ as active agent, to assess its inhibiting activity against two fungi isolated from an indoor biodeteriorated substrate [24], Alternaria alternata and Chaetomium globosum, for future application as biocide in antimicrobial coatings.

The synthesis of these silicas represents an environmentfriendly alternative, in concordance with the trend of the new antimicrobial formulation to replace traditional biocides. The fungi were selected by their ability to grow and deteriorate different materials, especially biofilms, in addition to the negative effect that they have on human health $[25,26]$.

\section{Experimental section}

\subsection{Materials}

The materials tetraethylorthosilicate, also named tetraethoxysilane, $\left(\mathrm{Si}\left(\mathrm{OCH}_{3}\right)_{4}\right)$ (TEOS), and methyltrimethoxysilane $\left(\mathrm{CH}_{3} \mathrm{Si}\left(\mathrm{OCH}_{3}\right)_{3}\right)$ (MTMS) were used as silica precursors; acetic acid $(99.99 \%)(\mathrm{AcH})$, hydrochloric acid $(99.99 \%)$ $(\mathrm{HCl})$, and molybdophosphoric acid $\left.\left(\mathrm{H}_{3}\left[\mathrm{P}\left(\mathrm{Mo}_{3} \mathrm{O}_{10}\right)_{4}\right)\right] \cdot \mathrm{xH}_{2} \mathrm{O}\right)$ (HPA) as catalysts; absolute ethanol $\left(\mathrm{CH}_{2} \mathrm{CH}_{3} \mathrm{OH}, 99.9 \%\right)$ $(\mathrm{EtOH})$ and distilled water as solvents in all the synthesis. $\left(\mathrm{NO}_{3}\right)_{2} \mathrm{Cu}$ was added in the necessary quantity.

The sol-gel method was used to synthesize the solids based on silica, under nitrogen atmosphere. Twelve samples were obtained using tetraethoxysilane $\left(\mathrm{Si}\left(\mathrm{OCH}_{3}\right)_{4}\right)$ (TEOS) and methyltrimethoxysilane $\left(\mathrm{CH}_{3} \mathrm{Si}\left(\mathrm{OCH}_{3}\right)_{3}\right)$ (MTMS) as silica precursors. In order to obtain different structures of siliceous gels, acetic acid $(99.99 \%)(\mathrm{AcH})$, hydrochloric acid $(99.99 \%)(\mathrm{HCl})$ and molybdophosphoric acid $\left(\mathrm{H}_{3-}\right.$ $\left.\left[\mathrm{P}\left(\mathrm{Mo}_{3} \mathrm{O}_{10}\right)_{4}\right] \cdot \mathrm{xH}_{2} \mathrm{O}\right)(\mathrm{HPA})$ were used as catalysts, whereas absolute ethanol $\left(\mathrm{CH}_{2} \mathrm{CH}_{3} \mathrm{OH}, 99.9 \%\right)(\mathrm{EtOH})$ and distilled water were used as solvents in all the synthesis.

In the synthesis with acetic and hydrochloric acids, the molar ratios of the reagents were 1:1.17:5:3.73 for precursor/catalyst/solvent/water, respectively. The amount of each component was obtained from previous assays of the research group to obtain, approximately, $10 \mathrm{~g}$ of silica. In the samples prepared using HPA, this reagent was added in order to reach a final concentration in the solid of $11 \%$ $(\mathrm{w} / \mathrm{w})$ and $\left(\mathrm{NO}_{3}\right)_{2} \mathrm{Cu}$ was added in the proper amount to occupy the half of the acid sites of HPA $\left(\mathrm{H}_{1.5} \mathrm{Cu}_{1.5}\right)$.

To obtain the different solids, a portion of solvent, specific catalyst, alkoxide precursor and copper were incorporated and put into a beaker, and the addition of the remaining amount of ethanol was then carried out. Only in the synthesis with $\mathrm{HCl}$, the catalyst was added at the end of the procedure. Subsequently, a slow addition of water was carried out and the mixture was stirred for $2 \mathrm{~h}$. Finally, the wet gel particles were dried at room temperature and atmospheric pressure up to complete solidification. The reagents and the nomenclature for all the samples are shown in Table 1.

\subsection{Characterization of the solids}

\subsubsection{Potentiometric titration with $n$-butylamine}

The evaluation of the acidic properties of solids was achieved by potentiometric titration with $n$-butylamine, carried out in a Metrohm 794 Basic Titrino titrator 
Table 1 Composition and nomenclature used for the prepared samples

\begin{tabular}{llll}
\hline Sample & Precursor & Catalyst & Active phase \\
\hline ST-HAc & TEOS & AcH & \\
ST-HCl & TEOS & $\mathrm{HCl}$ & \\
ST-H & TEOS & HPA & \\
ST-HCu & TEOS & HPA & $\mathrm{Cu}\left(\mathrm{NO}_{3}\right)_{2}$ \\
SM-HAc & MTMS & AcH & \\
SM-HCl & MTMS & HCl & \\
SM-H & MTMS & HPA & \\
SM-HCu & MTMS & HPA & $\mathrm{Cu}\left(\mathrm{NO}_{3}\right)_{2}$ \\
STM-HAc & TEOS-MTMS & AcH & \\
STM-HCl & TEOS-MTMS & HCl & \\
STM-H & TEOS-MTMS & HPA & \\
STM-HCu & TEOS-MTMS & HPA & $\mathrm{Cu}\left(\mathrm{NO}_{3}\right)_{2}$ \\
\hline
\end{tabular}

(Switzerland), with a double-junction electrode. An nbutylamine solution in acetonitrile $(0.025 \mathrm{~N})$ was added, at a $0.025 \mathrm{~mL} / \mathrm{min}$ rate, to $0.025 \mathrm{~g}$ of sample, previously suspended in acetonitrile $(45 \mathrm{~mL})$, and stirred for $3 \mathrm{~h}$.

\subsubsection{Textural properties}

The textural properties of the silicas, such as the specific surface area $\left(S_{\mathrm{BET}}\right)$, were determined in Micromeritics Accusorb 2100 equipment (USA), using $\mathrm{N}_{2}$ as absorbable gas.

\subsubsection{X-ray diffraction}

The X-ray diffraction (XRD) patterns were obtained in Philips (Holland) PW-1390 (channel control) and PW-1394 (motor control) equipment coupled to a scanning graphical recorder, using $\mathrm{Cu} \mathrm{K} \alpha(\alpha=1.5417 \AA)$ radiation, Ni filter, $20 \mathrm{~mA}$ and $40 \mathrm{kV}$ in the voltage source, a 5-60 $2 \theta$ scanning angle range, a scanning rate of $2 \% \mathrm{~min}$ and 2000 counts/s for the amplitude of the vertical scale.

\subsubsection{Scanning electron microscopy}

Scanning electron microscopy (SEM) was used to obtain different micrographs of the solids, in Philips 505 equipment (Holland), using a voltage of $15 \mathrm{kV}$. Samples were supported on graphite and metallized with a sputtered gold film. The micrographs were obtained with an ADDAII acquisition device (Soft Imaging System).

\subsubsection{FT-IR}

FT-IR spectra were obtained using Bruker IFS 66 equipment and pellets of the sample in $\mathrm{KBr}$, measured in a range between 400 and $4000 \mathrm{~cm}^{-1}$.

\subsubsection{Antimicrobial activity}

Fungi, A. alternata and C. globosum, previously isolated from biodeteriorated surfaces [27] were used as bioindicators to evaluate the antifungal activity of the silicas with HPA inside (control) and with HPA-Cu. Sub-cultures were obtained into Petri dishes from the isolates previously mentioned. The solid culture medium (CM-agar) was composed of agar, $1.5 \mathrm{~g}$; dextrosa, $1 \mathrm{~g}$; peptone, $0.5 \mathrm{~g}$; $\mathrm{KH}_{2} \mathrm{PO}_{4}, 0.1 \mathrm{~g} ; \mathrm{MgSO}_{4} \cdot 7 \mathrm{H}_{2} \mathrm{O}, 0.05 \mathrm{~g}$; and distilled water.

The solids with inhibitory activity were evaluated in vitro as fungal growth inhibition on agar plates [24, 25] with different concentrations against the fungal growth $(A$. alternata and C. globosum). Spores were removed from the sub-cultures prepared previously and deposited in a flask $(5 \mathrm{~mL})$ of physiological solution containing $\mathrm{NaCl}[0.85 \%$ $(\mathrm{w} / \mathrm{v})]$ and Tween $20[0.0005 \%(\mathrm{w} / \mathrm{v})]$, in order to obtain a suspension. The concentration of spores was adjusted to $0.3-0.5 \times 10^{6}$ spores $/ \mathrm{mL}$ employing a Neubauer chamber.

Plates with $15 \mathrm{~mL}$ of CM-agar were prepared with different concentrations of the studied solids $(0.1,0.5$ and $1.0 \mathrm{mg} / \mathrm{mL}$ in relation to $\mathrm{Cu}$ content), as well as the control (without copper) and the other without the addition of any agent (only CM-agar). The CM-agar plates were inoculated with $20 \mu \mathrm{L}$ of each fungal suspension in a single point located at the center and incubated at $25^{\circ} \mathrm{C}$. After 10 days, the average diameter of fungal colony was recorded and the inhibition effect was calculated according to the following equation [25]:

$I=[(C-E) / C] \times 100$

where $I$ is inhibition (\%), $C$ and $E$ are the average colony diameter of the mycelium growth of the controls and the evaluated solid plates, respectively. The data refer to the results of the last day of growth, applying three parallel measurements to obtain the standard deviations [25]. Through these data, the minimum inhibitory concentration (MIC), which was defined as the lowest tested concentration where no fungal growth was observed, is obtained.

\section{Results and discussion}

\subsection{Characterization of the solids}

\subsubsection{Potentiometric titration and textural properties}

The initial electrode potential measured $\left(E_{\mathrm{i}}\right)$, the specific surface area $\left(S_{\mathrm{BET}}\right)$, the pore volume and the mean pore size of the prepared solids are shown in Table 2.

It should be noted that the $\mathrm{SM}-\mathrm{HCl}$ sample synthesized with MTMS as precursor and $\mathrm{HCl}$ as catalyst could not be characterized due to its different gelification point. 
Table 2 Acidity and textural properties of the solids synthesized

\begin{tabular}{lcclc}
\hline Sample & $E_{\mathrm{i}}(\mathrm{mV})$ & $S_{\text {BET }}\left(\mathrm{m}^{2} / \mathrm{g}\right)$ & Pore volume $\left(\mathrm{cm}^{3} / \mathrm{g}\right)$ & Pore size $(\AA)$ \\
\hline ST-HAc & 137 & 464.0 & 0.2 & 18.7 \\
ST-HCl & 520 & 490.6 & 0.7 & 55.2 \\
ST-H & 440 & 321.1 & 0.2 & 22.9 \\
ST-HCu & 275 & 527.3 & 0.2 & 18.6 \\
SM-HAc & 17 & 2.6 & - & 43.3 \\
SM-H & 585 & 4.4 & - & 22.4 \\
SM-HCu & 260 & 6.0 & - & 103.5 \\
STM-HAc & 31 & 679.2 & 0.3 & 19.9 \\
STM-HCl & 530 & 520.5 & 0.8 & 63.4 \\
STM-H & 310 & 440.8 & 0.2 & 19.6 \\
STM-HCu & 370 & 524.5 & 0.2 & 16.9 \\
\hline
\end{tabular}

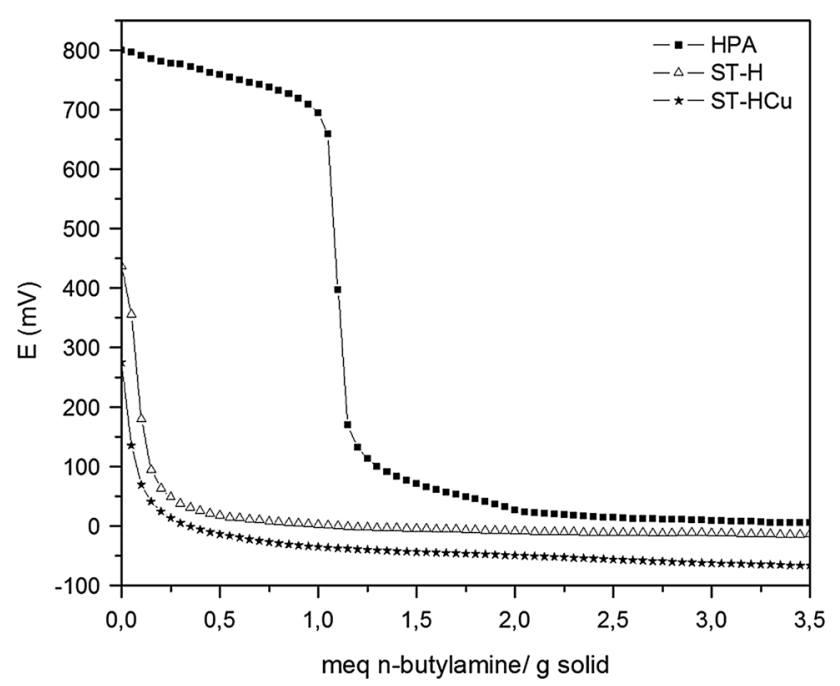

Fig. 1 Potentiometric curves of the ST-H, ST-HCu samples, and heteropolyacid (HPA)

As for the estimation of the acidic properties, Fig. 1 shows the potentiometric curves of different samples prepared with TEOS and the curve corresponding to the commercial heteropolyacid (HPA). In relation to the potentiometric titration, it is based on the difference in the electrode potential, which is determined mainly by the acid environment around the membrane, therefore, the measured electrode potential is an indicator of the acidic properties of the dispersion of solid particles. The initial electrode potential $\left(E_{\mathrm{i}}\right)$ indicates the maximum acid strength of the sites, and the value of meq amine/g solid, where the plateau is reached, indicates the total number of acid sites [28]. On the other hand, the maximum acid strength of the surface sites may be classified according to the following scale: very strong sites, $E_{\mathrm{i}}>100 \mathrm{mV}$; strong sites, $0<E_{\mathrm{i}}<\mathrm{m} 100 \mathrm{mV}$; weak sites, $-100<E_{\mathrm{i}}<0 \mathrm{mV}$; and very weak sites, $E_{\mathrm{i}}<-100 \mathrm{mV}$ [29]. When acetic or hydrochloric acids were used in the synthesis, the variation of $E_{\mathrm{i}}$ was important and, particularly, the quantity of acidic remaining sites in the solid when $\mathrm{HCl}$ was used. Incorporating HPA as catalyst, the potentiometric curve obtained was clean, with an initial high acidic strength and few acidic sites, meanwhile, the addition of $\mathrm{Cu}$ to the synthesis, monoprotic acidic sites were maintained, but the initial acidity decreased by the substitution of HPA protons by copper. When MTMS was used as precursor, the curves obtained were different at the initial acidity and the number of acidic sites. Although the acidity was lower when TEOS was used, these values should be appropriate for the use of the synthesized solids as antimicrobial fillers.

The samples where the silica precursors were mixed showed the same tendency for maximum acid strength and acidic sites, raising or lowering in a similar manner. Figure 2 shows the $E_{\mathrm{i}}$ values of all the samples, and an oscillation between values near 0 up to near $600 \mathrm{mV}$ is observed. The acidity obtained in all the cases is sufficient to be used as fillers in the case of coatings.

As it can be observed in Table 2, the samples with higher $S_{\mathrm{BET}}$ values are those synthesized using TEOS as precursor, ST-HAc, ST-HCl, ST-H simple samples or STM-HAc, STM-HCl, STM-H mixed samples. In the case where only MTMS was used as precursor, $S_{\mathrm{BET}}$ is very low (almost coincident with the error of the technique), but when $\mathrm{Cu}$ is incorporated in the synthesis, the area increases. About the pore volume, the solids with higher value were those synthesized with $\mathrm{HCl}$ as catalyst. The $\mathrm{N}_{2}$ adsorption-desorption curves showed by the synthesized samples indicate that the variation in the pore size and the surface area are consistent with the results of the curve hysteresis. High-quality hysteresis was observed for the samples prepared with the use of TEOS as precursor and when TEOS is mixed with MTMS.

\subsubsection{X-ray diffraction and scanning electron microscopy}

The XRD diagrams (not shown) of the ST-HCl, ST-HCu, STM-HCl, STM-HAc and STM-H samples showed 
Fig. 2 Initial electrode potential of the synthesized samples

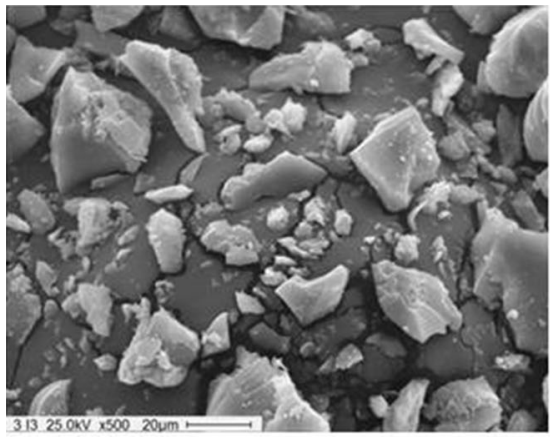

ST-HAC
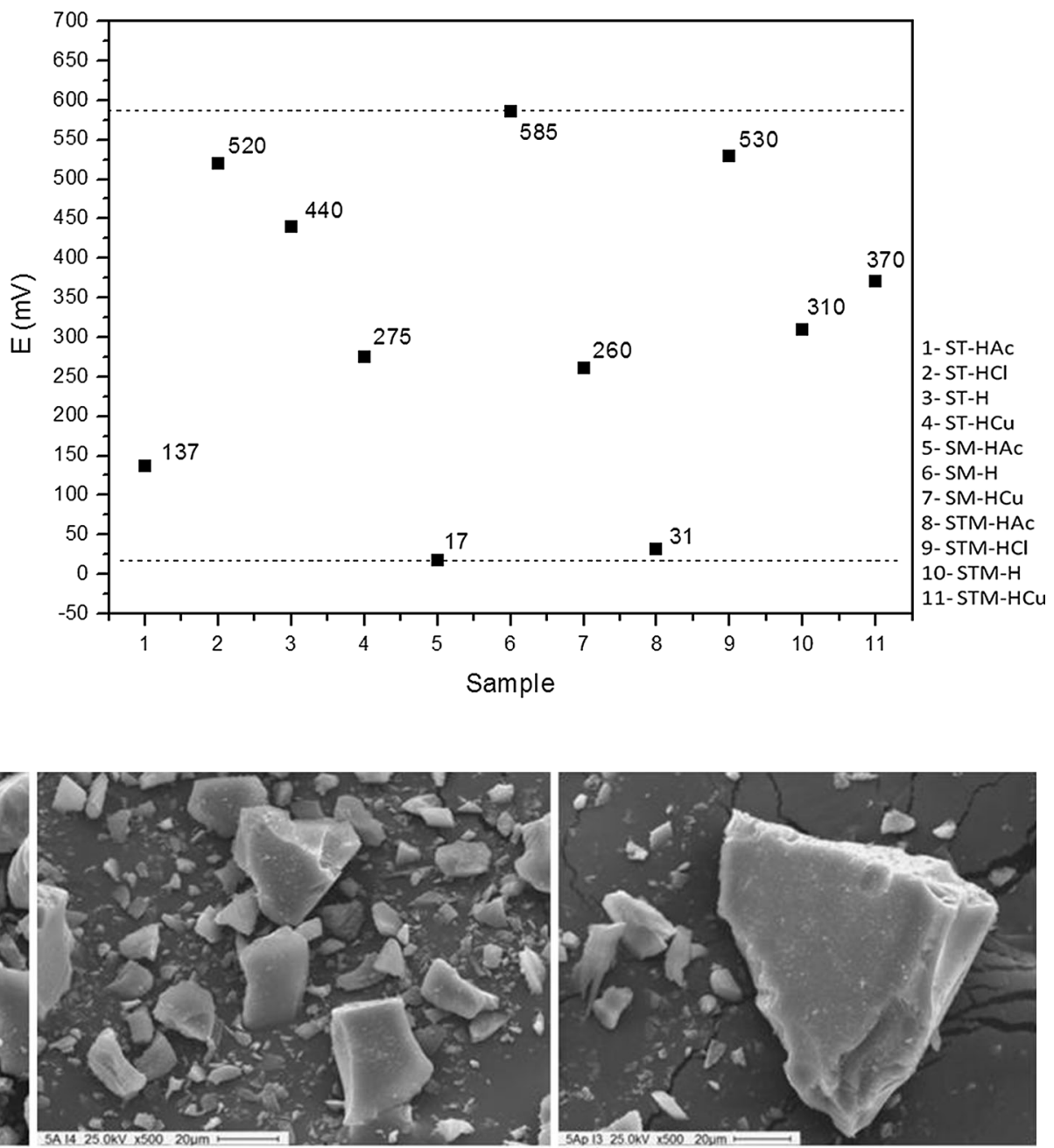

ST-H

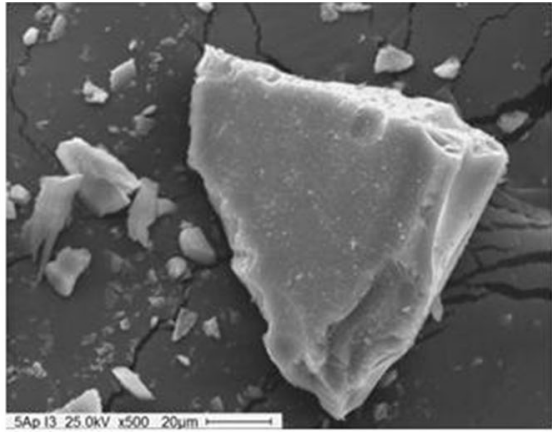

$\mathrm{ST}-\mathrm{HCu}$

Fig. 3 SEM micrographs of the ST-HAc (pure silica), ST-H and ST-HCu samples

patterns with wide bands, assigned to amorphous silica, no matter which of the precursor was used.

On the other hand, the micrographs of the samples synthesized with TEOS, at a $500 \times$ magnification, are displayed in Fig. 3. They are similar in their morphology to the pure silica (ST-HAc sample) though in all the cases they are modified silica.

In relation with SEM of the SM-HCu sample (Fig. 4), a homogeneous distribution (mapping) of the components in the silica matrix was observed. The other samples containing $\mathrm{Cu}$ presented a similar behavior.

\subsubsection{FT-IR}

In order to understand the interactions that occur in the solids, the synthesized compounds were studied by FT-IR. When evaluating the effects of observable interactions in the FT-IR spectrum, it was decided to follow the method of identification through similarity of bands for the samples containing
HPA with Keggin structure. A broad band between 1100 and $964 \mathrm{~cm}^{-1}$, and two bands at 800 and $470 \mathrm{~cm}^{-1}$, which are the characteristic bands of silica, can be observed in all the samples. The HPA presents four characteristic bands at 1064 , 962,871 and $780 \mathrm{~cm}^{-1}$. The spectrum of copper nitrate was also plotted in Figs. 5, 6 and 7 in order to compare with the spectra of the ST-HCu, SM-HCu and STM-HCu samples because $\mathrm{Cu}$ formed part of them in these solids. The HPA characteristic bands may be slightly shifted by interactions between the heteropolyacid and copper nitrate. In Figs. 5 and 6 , the silica pure bands can be observed when TEOS or MTMS are used as precursors, and when mixing TEOS and MTMS to prepare the solids (Fig. 7), very similar bands to the previous cases were present.

Regarding Figs. 5 and 6, it is evident that the $\mathrm{SM}-\mathrm{HCu}$ sample presented the bands of copper nitrate, but when TEOS was used in the ST-HCu sample, the main $\mathrm{Cu}$ bands disappear because copper strongly interacts with the HPA. But it is clear (Fig. 7) that when a mixture of precursors is 

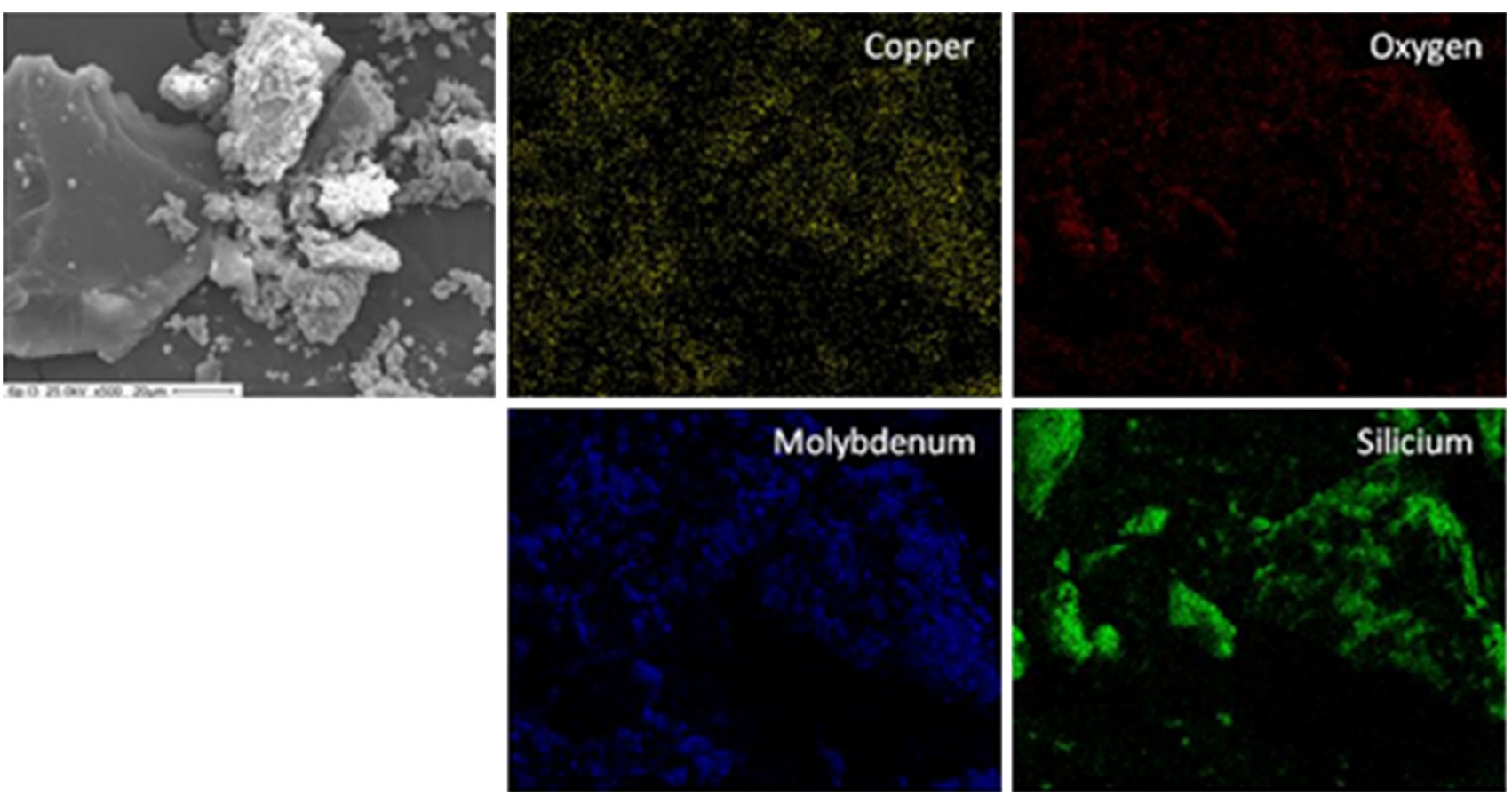

Fig. 4 SEM and mapping of the SM-HCu sample

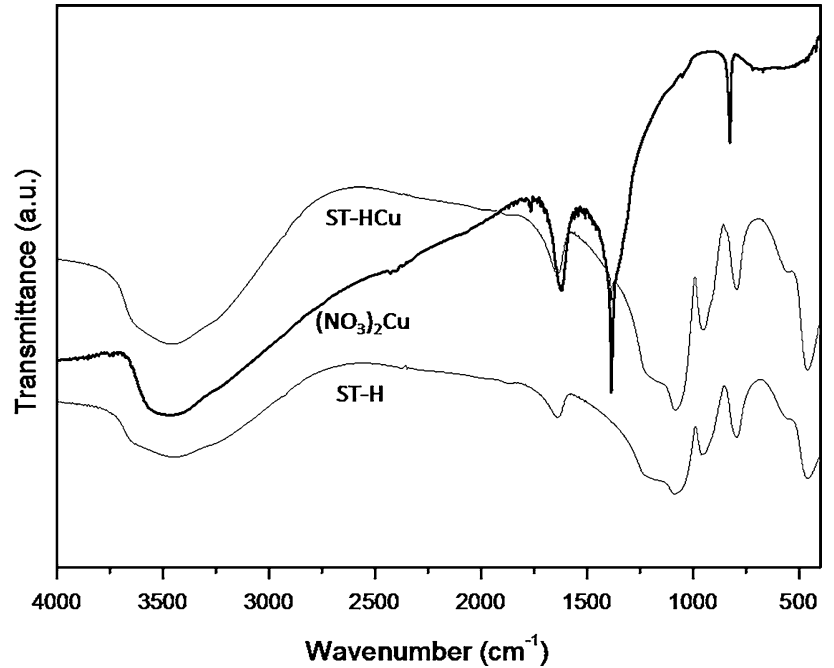

Fig. 5 FT-IR spectra of the synthesized ST-H and ST-HCu samples, and of bulk $\left(\mathrm{NO}_{3}\right)_{2} \mathrm{Cu}$

used, the $\mathrm{Cu}$ bands are faintly visible, which could be attributed to interaction between HPA and copper.

\subsubsection{Antimicrobial activity}

Antifungal activity was evaluated by measuring the fungal growth on CM-agar plates. The average diameter of each culture tested (A. alternata and C. globosum) for the different studied solids is shown in Figs. 8 and 9, respectively. Here it stands out the difference between fungal growth in

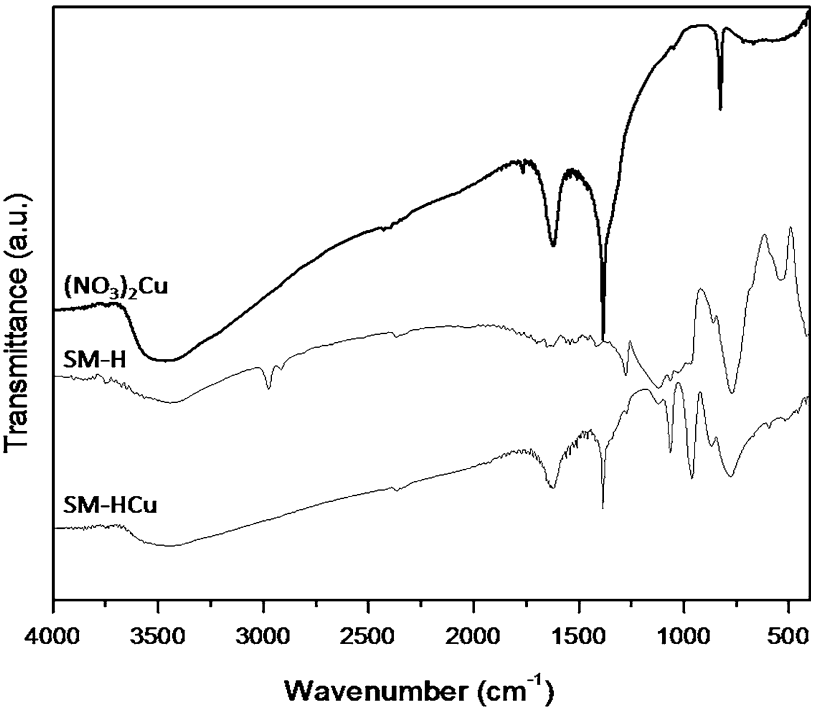

Fig. 6 FT-IR spectra of the synthesized SM-H and SM-HCu samples, and of bulk $\left(\mathrm{NO}_{3}\right)_{2} \mathrm{Cu}$

$\mathrm{SM}-\mathrm{HCu}$ and STM-HCu samples and their respective solid controls; it seems that the addition of $\mathrm{Cu}$ provided greater inhibitory activity to the SM-H solid. Photographs taken with both isolates after an incubation period of 10 days are shown in Fig. 10. On the other hand, the solid ST-H showed a similar inhibitory effect regardless of the presence of $\mathrm{Cu}$ with both fungal isolates.

Table 3 shows the inhibition effect (\%) against both fungal isolates determined according to Eq. (1). The SM- 


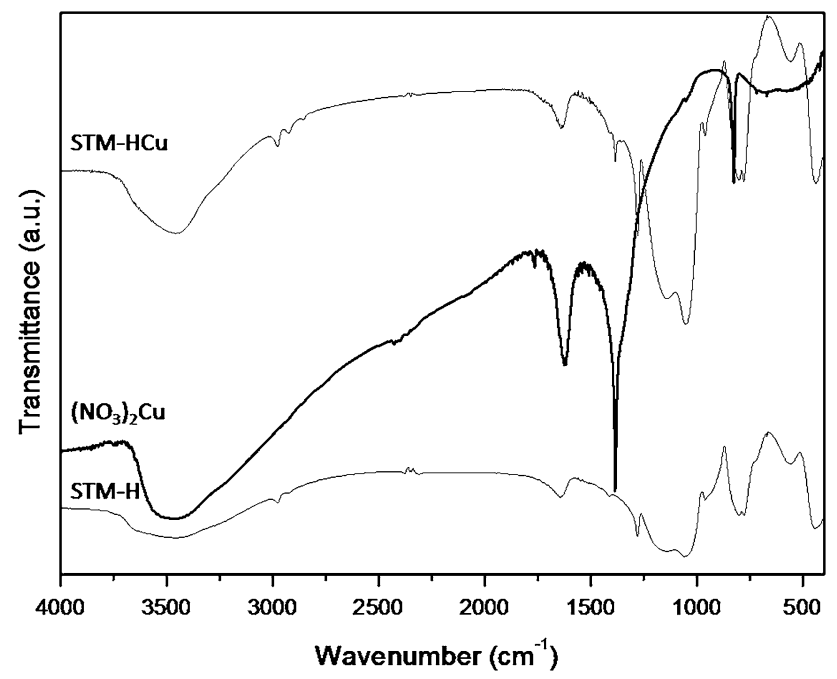

Fig. 7 FT-IR spectra of the synthesized STM-H and STM-HCu samples, and of bulk $\left(\mathrm{NO}_{3}\right)_{2} \mathrm{Cu}$

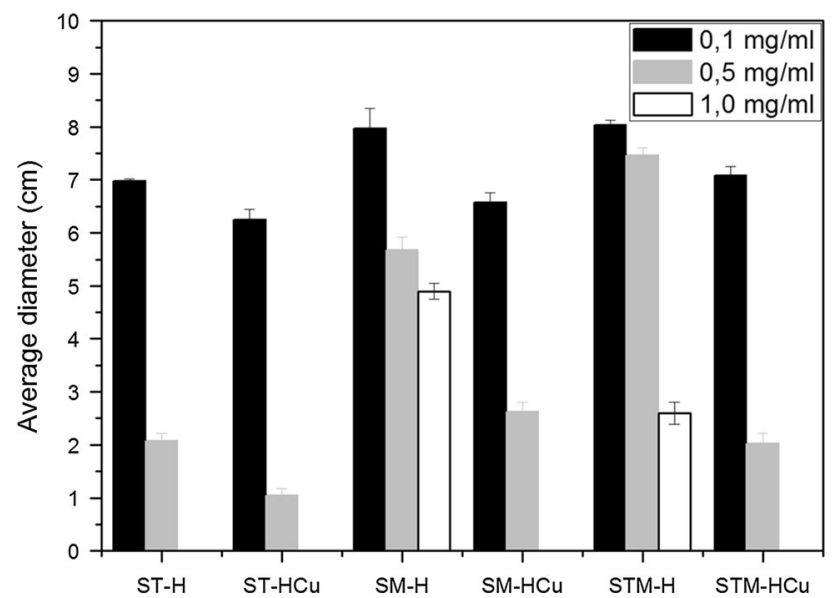

Fig. 8 A. alternata, average growth diameter with different solids containing $\mathrm{Cu}$ and their respective controls

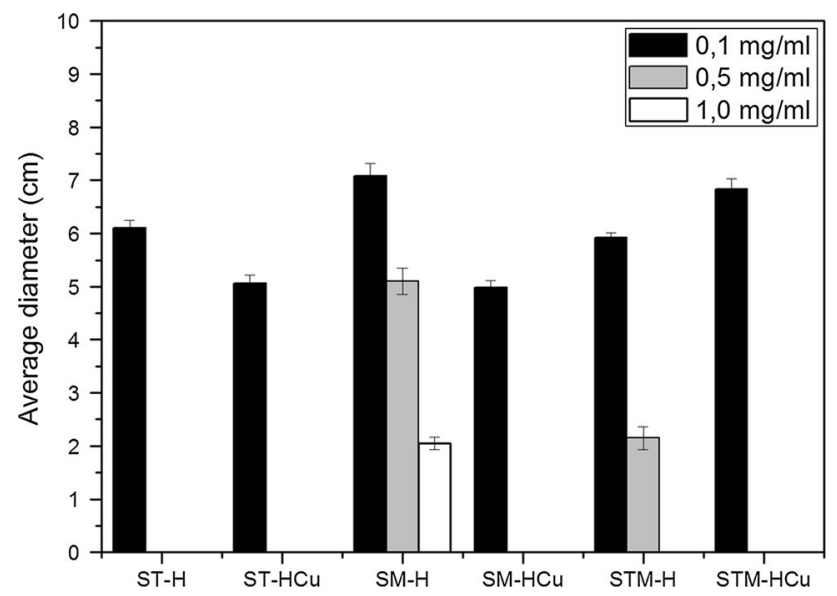

Fig. 9 C. globosum, average growth diameter with different solids containing $\mathrm{Cu}$ and their respective controls

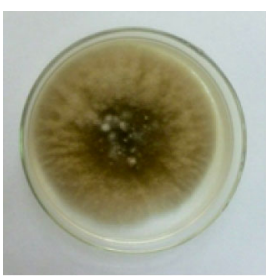

(a) Control

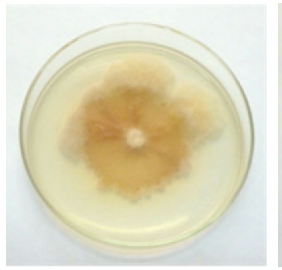

(d) Control

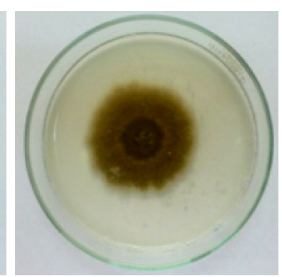

(b) $\mathrm{SM}-\mathrm{H}$

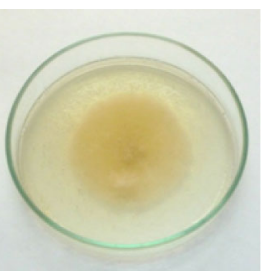

(e) $\mathrm{SM}-\mathrm{H}$

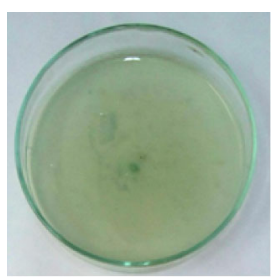

(c) $\mathrm{SM}-\mathrm{HCu}$

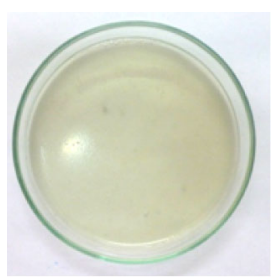

(f) $\mathrm{SM}-\mathrm{HCu}$
Fig. 10 A. alternata (a)-(c) and C. globosum (d)-(f) growth on CMagar plates after 10 days at $25^{\circ} \mathrm{C}, 1.0 \mathrm{mg} / \mathrm{mL}$ (b)-(c) and $0.5 \mathrm{mg} / \mathrm{mL}$ (e)-(f)

Table 3 Inhibitory activity of the modified silica matrix against $A$. alternata and C. globosum fungi for different copper content

\begin{tabular}{|c|c|c|c|c|c|c|}
\hline \multirow[t]{4}{*}{ Samples } & \multicolumn{6}{|c|}{ Inhibition effect (\%) } \\
\hline & \multicolumn{3}{|c|}{ A. alternata } & \multicolumn{3}{|c|}{ C. globosum } \\
\hline & \multicolumn{6}{|c|}{ Copper concentration $(\mathrm{mg} / \mathrm{mL})$} \\
\hline & 0.1 & 0.5 & 1.0 & 0.1 & 0.5 & 1.0 \\
\hline $\mathrm{ST}-\mathrm{H}^{\mathrm{a}}$ & 19.4 & 76.2 & 100 & 19.1 & 100 & 100 \\
\hline $\mathrm{ST}-\mathrm{HCu}$ & 24.0 & 78.8 & 100 & 31.7 & 100 & 100 \\
\hline $\mathrm{SM}-\mathrm{H}^{\mathrm{a}}$ & 8.1 & 34.6 & 43.4 & 6.0 & 32.4 & 72.8 \\
\hline $\mathrm{SM}-\mathrm{HCu}$ & 19.6 & 68.2 & 100 & 33.0 & 100 & 100 \\
\hline $\mathrm{STM}-\mathrm{H}^{\mathrm{a}}$ & 2.4 & 9.4 & 68.5 & 7.0 & 71.1 & 100 \\
\hline STM-HCu & 14 & 75.3 & 100 & 9.3 & 100 & 100 \\
\hline
\end{tabular}

${ }^{a}$ Control

$\mathrm{HCu}$ and STM-HCu samples enhanced the antifungal activity compared to the copper free solids against both fungi. This effect is increased in the case of $C$. globosum fungus.

The MIC was defined as the lowest concentration of copper in the solids under study that produced a total inhibition of fungal growth. When tested, MIC was $1 \mathrm{mg} / \mathrm{mL}$ for A. alternata fungus and $0.5 \mathrm{mg} / \mathrm{mL}$ for $C$. globosum fungus. The results showed that the functionalized solids presented a higher inhibitory effect against $C$. globosum fungus.

\section{Conclusions}

The synthesis of the proposed solids to be used as biocides in antimicrobial coatings was possible to be carried out through the addition of copper. The evaluation of the 
textural properties, acidity, morphology and antifungal activity was performed. In relation to the textural properties, it was observed an increase in the specific surface area $\left(S_{\mathrm{BET}}\right)$ when TEOS was used as precursor in the synthesis, instead of MTMS. When both precursors were used in order to obtain a mixed solid, the area was higher, increasing significantly with the addition of copper. Regarding the pore volume, the highest value is presented by those samples synthesized with $\mathrm{HCl}$ as a hydrolysis catalyst.

Concerning the acidity, when acetic acid or hydrochloric acid was used, the variation of the initial potential is evident, and the amount of remaining acid sites in the solid by the use of $\mathrm{HCl}$ is higher. When the HPA is used alone, the titration curve is clean showing high acidity though the acid sites are fewer; when copper is added to the synthesis, the shape of the potentiometric curve remains the same, resulting in monoprotic acid sites; however, when HPA protons are replaced with copper, the curve decreases. When MTMS is used as a precursor, the potentiometric titration curves appear different in initial acid strength and number of acid sites. However, even if the acidity is lower than when TEOS is used, it should be feasible for the synthesized solids to be used as antimicrobial fillers. In the case of the samples of silica prepared using a precursor mixture, with the HPA and copper, they all have the same trend of the acid sites and acid strength, moving up or down, even the behavior is similar to that when the precursor was used alone.

Though modified, the morphology of silica remains the same. By analyzing X-ray diffraction results, the amorphous characteristics of the obtained silica are evidenced and, regarding what was observed by FT-IR, the samples showed bands corresponding to the compounds with which silica was modified.

It was possible to evaluate the antifungal activity of the copper-doped solid through the inhibition test against the two fungi of interest (A. alternata and C. globosum) and the inhibition percentage determined for each case. SM$\mathrm{HCu}$ and STM-HCu samples showed an increased antifungal activity by totally inhibiting the growth of both fungi, with lower concentrations compared to the other. Therefore, the methodology achieved in this preliminary study is successful to guide the selection of a suitable ecological biocide from a list of possible antifungal agents.

Acknowledgments The authors thank M. Theiller (SEM), G. Valle (FT-IR), E. Soto $\left(S_{\mathrm{BET}}\right)$ for their contribution, and UNLP and CONICET for the financial support.

\section{References}

1. Weber DJ, Rutala WA (2013) Self-disinfecting surfaces: review of current methodologies and future prospects. Am J Infect Control 41:S31-S35
2. Srey S, Jahid IK, Ha SD (2013) Biofilm formation in food industries: a food safety concern. Food Control 31:572-585

3. Simões M, Simões LC, Vieira MJ (2010) A review of current and emergent biofilm control strategies. Food Sci Technol 43:573-583

4. Glinel K, Thebault P, Humblot V, Pradier CM, Jouenne T (2012) Antibacterial surfaces developed from bio-inspired approaches. Acta Biomater 8:1670-1684

5. Barlett M, Vesco S, Tagliaferri V (2014) Self-cleaning and selfsanitizing coatings on plastic fabrics: design, manufacture and performance. Colloids Surf B 120:71-80

6. World Health Organization (WHO) Regional Office for Europe, WHO guidelines for indoor air quality: dampness and mould 2009, http://www.euro.who.int

7. Coad BR, Kidd SE, Ellis DH, Griesser HJ (2014) Biomaterials surfaces capable of resisting fungal attachment and biofilm formation. Biotech Adv 32:296-307

8. Gu JD (2003) Microbiological deterioration and degradation of synthetic polymeric materials: recent research advances. Int Biodeter Biodegr 52:69-91

9. Gaylarde CC, Morton LHG, Loh K, Shirakawa MA (2011) Biodeterioration of external architectural paint films - a review. Int Biodeter Biodegr 65:1189-1198

10. Gaylarde CC, Gaylarde PM (2005) A comparative study of the major microbial biomass of biofilms on exteriors of buildings in Europe and Latin America. Int Biodeter Biodegr 55:131-139

11. Johns K (2003) Hygienic coatings: the next generation. Surf Coat Int 86:101-110

12. Lindner W (2004) Surface coatings. In: Paulus W (ed) Directory of microbicides for the protection of materials: a handbook. Kluwer, Dordrecht, pp 347-375

13. Tiller JC, Liao CJ, Lewis K, Klibanov AM (2001) Designing surfaces that kill bacteria on contact. Proc Natl Acad Sci 98:5981-5985

14. Copello GJ, Teves S, Degrossi J, D'Aquino M, Desimone MF, Díaz LE (2008) Proving the antimicrobial spectrum of an amphoteric surfactant-sol-gel coating: a food-borne pathogen study. J Ind Microbiol Biotechnol 35:1041-1046

15. Jaiswal S, Bhattacharya K, Sullivan M, Walsh M, Creaven BS, Laffir F, Duffy B, McHale P (2013) Non-cytotoxic antibacterial silver-coumarin complex doped sol-gel coatings. Colloids Surf B 102:412-419

16. Kim JS, Kuk E, Yu KN, Kim J, Park SJ, Lee HJ, Kim SH, Park YK, Park YH, Hwang CY, Kim YK, Lee YS, Jeong DH, Cho MH (2007) Antimicrobial effects of silver nanoparticles. Nanomed NBM 3:95-101

17. Ramyadevi J, Jeyasubramanian K, Marikani A, Rajakumar G, Rahuman AA (2012) Synthesis and antimicrobial activity of copper nanoparticles. Mat Lett 71:114-116

18. Hogg S (2005) Essential microbiology. Wiley, Chichester

19. Raffi M, Hussain F, Bhatti TM, Akhter JI, Hameed A, Hasan MM (2008) Antibacterial characterization of silver nanoparticles against E. Coli ATCC-15224. J Mater Sci Technol 24:192-196

20. Ren G, Hu D, Cheng EWC, Vargas-Reus MA, Reip P, Allaker RP (2009) Int J Antimicrob Agents 33:587-590

21. Ruparelia JP, Chatterjee AK, Duttagupta SP, Mukherji S (2008) Strain specificity in antimicrobial activity of silver and copper nanoparticles. Acta Biomater 4:707-716

22. Ballini R (2009) Eco-friendly synthesis of fine chemicals. In: Clark JH, Kraus GA (eds) The Royal Society of Chemistry, Cambridge

23. McDonough $\mathrm{W}$, Braungart $\mathrm{M}$, Anastas PT, Zimmerman JB (2003) Peer reviewed: applying the principles of green engineering to cradle-to-cradle design. Env Sci Technol 37:434A$441 \mathrm{~A}$

24. Bellotti N, Salvatore L, Deyá C, DelPanno MT, del Amo B, Romagnoli R (2013) Colloids Surf B 104:140-144 
25. Vági E, Simándi B, Suhajda A, Héthelyi E (2005) Essential oils composition and antimicrobial activity of Origanum majorana $\mathrm{L}$ extracts obtained with ethyl alcohol and supercritical carbon dioxide. Food Res Int 38:51-57

26. Cooley JD, Wong WC, Jumper CA, Straus DC (2004) Fungi and the indoor environment: their impact on human health. Adv Appl Microbiol 55:1-30

27. Salvatore L, Romagnoli R, del Amo B, Bellotti N, Del Panno MT (2010) 3er. Encuentro de Jóvenes Investigadores en Ciencia y Tecnología de Materiales, SAM - UTN, Concepción del Uruguay
28. Villabrille P, Romanelli G, Quaranta N, Vázquez P (2010) Appl Catal B 96:379-386

29. Villabrille P, Vázquez P, Cáceres C, Blanco M (2002) Equilibrium adsorption of molybdosilicic acid solutions on carbon and silica: basic studies for the preparation of ecofriendly acidic catalysts. J Colloid Interfase Sci 251:151-159 